\title{
Evaluation of open access precipitation and temperature products using SWAT in Shiyang river basin, Northwest China
}

\author{
Gengxi Zhang ${ }^{a, b}$, Xiaoling Su $u^{a, b,{ }^{*}}$, Olusola O. Ayantobo ${ }^{c}$, Kai Feng ${ }^{a, b}$, Jing Guo ${ }^{d}$ \\ a College of Water Resources and Architectural Engineering, Northwest A \& F University, Yangling 712100, China; \\ gengxizhang@nwsuaf.edu.cn; xiaolingsu@nwafu.edu.cn; fengk0121@163.com \\ ${ }^{b}$ Key Laboratory for Agricultural Soil and Water Engineering in Arid Area of Ministry of Education, Northwest A E F \\ University, Yangling 712100, China; xiaolingsu@nwafu.edu.cn \\ ${ }^{c}$ Department of Water Resources Management and Agricultural-Meteorology, Federal University of Agriculture, PMB 2240, \\ Abeokuta 110282, Nigeria; ayantobooo@funaab.edu.ng \\ 'Chongqing University of Science and Technology, College of Mathematics and Physics, Chongqing 401331, China; \\ 2019010@cqust.edu.cn \\ * Correspondence: xiaolingsu@nwafu.edu.cn
}

\begin{abstract}
Precipitation and temperature are significant inputs for hydrological models. Currently, many satellite and reanalysis precipitation and air temperature datasets exist at different spatiotemporal resolutions at a global and quasi-global scale. This study evaluated the performances of three open-access precipitation datasets (gauge-adjusted research-grade Global Satellite Mapping of Precipitation (GSMaP_Gauge), Climate Hazards Group Infrared Precipitation with Station data (CHIRPS), Climate Forecast System Reanalysis(CFSR)) and CFSR air temperature dataset in driving the Soil and Water Assessment Tool (SWAT) model required for the monthly simulation of streamflow in the upper Shiyang River Basin of northwest China. After a thorough comparison of six model scenarios with different combinations of precipitation and air temperature inputs, the following conclusions were drawn: (1) Although the precipitation products had similar spatial patterns, however, CFSR differs significantly by showing an overestimation; (2) CFSR air temperature yielded almost identical performance in the streamflow simulation than the measured air temperature from gauge stations; (3) among the three open-access precipitation datasets, CHIRPS produced the best performance. These results suggested that the CHIRPS precipitation and CFSR air temperature datasets which are available at high spatial resolution (0.05), could be a promising alternative open-access data source for streamflow simulation in the case of limited access to desirable gauge data in the data-scarce area.
\end{abstract}

Keywords: Remote sensing; Precipitation; Temperature; GSMaP_Gauge; CHIRPS; CFSR; SWAT

\section{Introduction}

Hydrological models are essential in explaining hydrological processes and supporting the operational management of water resources which is characterized by large spatio-temporal variability [1]. Precipitation and temperature are two necessary inputs required to drive hydrological models. Precipitation is among the most important components of the global water cycle, and its spatio-temporal variation deeply influences water resource availability in regions [2-4]. Therefore, accurate estimates of precipitation are not only important for water resources management but also 
for hydrological extreme forecasting, debris-flow and rainfall-triggered hazard forecasting [5,6]. However, obtaining accurate precipitation estimates is still a challenge due to its strong variability.

Precipitation is commonly measured in three ways: gauge observations, weather radar observations, and remotely sensed observations [7]. Ideally, a reasonably dense network of weather stations is needed to obtain reliable and accurate precipitation data that are adequate to effectively represent the weather condition at the basin scale [8]. However, gauge observations are subject to many limitations which include scarce stations, data gaps, reporting time delay, and limited accessibility to available data [2,9], which hinders hydrological predictions at gauge-scarce regions. Weather radars can provide reliable spatial coverage up to $\sim 300 \mathrm{~km}$ from the radar sites, however, radar observed precipitation products are often subjected to several limitations, such as beam blockage by mountains and high buildings, beam height changes, and uncertainties in the Z-R relationship used to derive precipitation rates from the intensity of radar reflectivity [10,11]. Additionally, weather radar network is restricted to areas with low power supply. In recent years, satellite remote sensing and reanalysis technologies have got increasing attention in providing highresolution precipitation estimates [12-15].

Tropical Rainfall Measuring Mission (TRMM), the first professional precipitation detection program, was launched in 1997 to study rainfall for weather and climate research (https://pmm.nasa.gov/trmm). Precipitation datasets retrieved from the passive microwave (PMW), calibrated visible and thermal infrared (Vis/IR), and PMW plus Vis/IR observations have promoted the rapid development of quasi-global information monitoring [6]. After over 17 years of productive data gathering, the instruments on TRMM were turned off on April 8, 2015. As TRMM's successor, the Global Precipitation Mission (GPM) managed by NASA and JAXA has provided the latest high spatiotemporal resolution of global precipitation products since March 2014 [16]. Three GSMaP products, i.e., the real-time GSMaP_NRT, the post-real-time GSMaP_MVK, and the gauge-adjusted research-grade product (i.e., GSMaP_Gauge) have been released since then [5]. Among these products, the GSMaP_Gauge which is based on the GSMap_MVK estimates and run by the Climate Prediction Center (CPC) has more accurate measurement. GSMaP_Gauge accurately produces 1 hourly, $0.1^{\circ}$ resolution global gridded rain rate for $60^{\circ} \mathrm{N}-60^{\circ} \mathrm{S}$ latitude band [17]. Although GSMaP usually has higher monitoring skills than other datasets, there are some shortcomings, such as performing worse for light and heavy rainfall [18], and overestimation of rainfall occurrences [19]. These show that the quality of satellite rainfall products varies with region, season, and elevation. Consequently, the absolute accuracy of satellite rainfall products is questionable and needs a thorough evaluation [20-22].

This study will employ the widely-used Soil and Water Assessment Tool (SWAT) model. For the SWAT community, Climate Forecast System Reanalysis (CFSR) datasets have been extensively used for hydrological simulation due to their ready-to-use format (http://globalweather.tamu.edu/). Several studies have been out carried using CFSR weather variables to drive the SWAT model for streamflow simulation. In some regions such as Lake Tana Basin, Ethiopia [8,23], and Southwest China [24], CFSR has been observed to achieve satisfactory streamflow simulation. On the contrary, CFSR generated unsatisfactory streamflow simulation in two upstream watersheds of the Three Gorges Reservoir in China [25] and two watersheds in the USA [26]. The aforementioned research showed that the CFSR data have limitations in some regions. Besides, these studies only evaluated the performance of CFSR precipitation data but did not comprehensively evaluate other weather variables (e.g. air temperature) from CFSR for hydrologicalmodelling. The minimum required weather data for the SWAT model include precipitation, maximum and minimum temperature. 
Therefore, it is important to explore the overall performance when CFSR air temperature data is combined with other better precipitation data to drive the SWAT model, particularly in regions where weather stations are sparse.

Besides GSMaP and CFSR datasets, there are many other satellite or reanalysis precipitation datasets in different resolutions at global or qusia-global scales [27]. It is worth noting that among the recently released datasets, the Climate Hazards Group Infrared Precipitation with Station data (CHIRPS) precipitation dataset (Funk et al., 2015) stands out by providing daily precipitation at the finest spatial resolution of $0.05^{\circ}$ (one grid representing around $25 \mathrm{~km}^{2}$ ) from 1981 to date [8,13]. CHIRPS merges global climatology, satellite estimates, and in-situ observations to produce precipitation data, which has been evaluated and compared with other precipitation products in many regions such as Tibetan Plateau [2,28], mainland China [29], Ethiopia[8], Northeast Brazil [30] among others. CHIRPS was found to be more accurate and better than other commonly used satellite or reanalysis precipitation products. Given its high resolution, long duration, and good performance, CHIRPS can be a good alternative data source in many aspects.

In this study, our objective is to evaluate the performance of using different combinations of precipitation datasets including the relatively new CHIRPS with CFSR air temperature datasets in driving the SWAT model for streamflow simulation in the Shiyang river basin. This will enable us to select suitable weather data from satellite and reanalysis sources.

\subsection{Study area and datasets}

\subsection{Study Area}

Shiyang river begins from the northern slope of the Qilian Mountains and ends at the Minqin oasis (Fig. 1). The Shiyang river basin which covers an area of about $41,400 \mathrm{~km}^{2}$, is one of the three inland river basins in the Hexi corridor [31,32]. Precipitation in this region has high spatio-temporal heterogeneity where in the southern mountain regions, the annual precipitation reaches approximately $600-300 \mathrm{~mm}$, while in the lower reaches, it's lower than $150 \mathrm{~mm}$, with nearly $81-89 \%$ occurring from May to October [33]. The upper reaches with an elevation of 2000-5000m are main source region for runoff, which has an area of about $1.1 \times 10^{4} \mathrm{~km}^{2}$, consisting of eight main sub-basins located upstream, including the Xida River basin, Dongda River basin, Xiying River basin, Jintai River basin, Zamu River basin, Huangyang River basin, Gulang River basin and Dajing River basin [34,35]. 


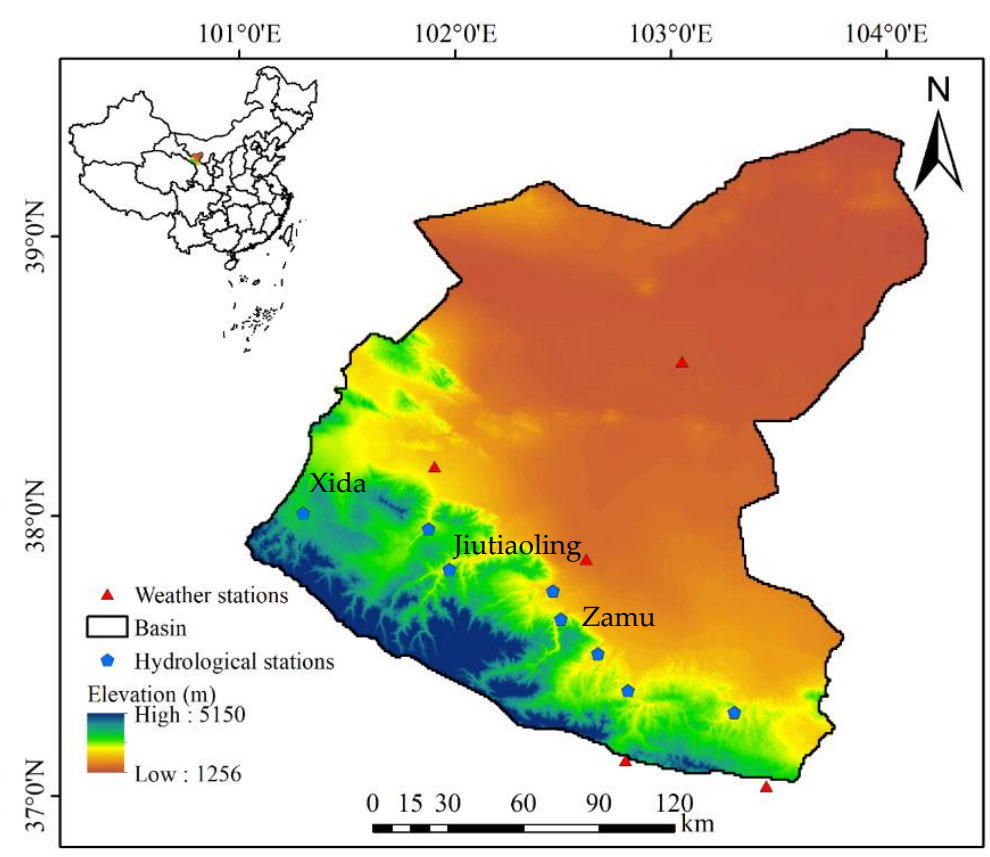

Fig. 1 Locations of the Shiyang River Basin, Streamflow Gauging Stations and Weather Stations.

\subsection{In-situ measurements from gauge stations}

The gauged meteorological data (daily precipitation, daily maximum temperature, minimum temperature) of five meteorological stations (Wuqiaoling, Menyuan, Wuwei, Yongchang, and Minqin) for 1984-2012 were provided by the National Meteorological Information Center of China Meteorological Administration (http://data.cma.cn/). Observed monthly discharge data for the study periods were obtained from the Hydrological Service of Gansu province. Also, we collected a spatially interpolated datasets of annual precipitation from the Resource and Environment Data Cloud Platform (http://www.resdc.cn/data.aspx?DATAID=229) as reference data.

\subsection{Remote sensing precipitation}

In this study, three satellite-based precipitations products were employed, which are the gaugeadjusted Global Satellite Mapping of Precipitation product (GSMAP_Gauge version 6) [36], version 2.0 of the Climate Hazards Group Infrared Precipitation with Stations (CHIRPS v2.0)[13], and National Centers for Environmental Prediction's (NCEP's) Climate Forecast System (CFSR)[37], which were obtained for 13 years periods (2000-2012).

GSMaP_Gauge product is corrected based on GSMaP-MVK (a pure satellite-based GSMaP product without correction by gauge data) and adjusted by Climate Prediction Center (CPC) global daily gauge data analysis [38,39]. GSMaP _Gauge with $0.1^{\circ}$ spatial resolution and 1-h temporal resolution covers latitude $60^{\circ} \mathrm{N}$ to $60^{\circ} \mathrm{S}$ and longitude $180^{\circ} \mathrm{W}$ to $180^{\circ} \mathrm{E}$ [6,36]. More information about the GSMaP products is available in the G-Portal data service system (http://www.gportal.jaxa.jp). The 1-hour GSMaP data were integrated into daily precipitation data.

The CFSR products are available at a spatial resolution of $0.31^{\circ}$ with 64 levels extending from the surface to $0.26 \mathrm{hPa}[8]$. The CFSR data spanning from 1979 to 2014 are available on the website (https:// globalweather.tamu.edu/) and popularizes its application in SWAT modelling community because it provides readily weather data (precipitation, air temperature, relative humidity, wind speed, and solar radiation) required by SWAT in the ready-to-use format. 
CHIRPS combines thermal infrared (TIR) observations, atmospheric reanalysis, and rainfall fields and precipitation measurements from more than 20,000 gauges globally. This data can be downloaded from the University of California, Santa Barbara (USA)(ftp://chgftpout.geog.ucsb.edu/pub/org/chg/products/CHIRPS2.0/global daily/)[2,40]. CHIRPS has a horizontal resolution of $0.05^{\circ}(5.4 \mathrm{~km})$ and spatial coverage $\left(50 \circ \mathrm{S}-50 \circ \mathrm{N}, 180^{\circ} \mathrm{W}-180 \circ \mathrm{E}\right)$ $[29,41]$.

\subsection{Methodology}

\subsection{SWAT setup}

The SWAT was developed by the USDA to simulate the quantity and quality of surface and groundwater and predict the impacts of land use, climate change, and land management practices on water resources, sediments, and agricultural production [32,42-44]. SWAT model divides the basin into several sub-basins and then constructs hydrological response units (HRU) based on land use and soil types to model hydrological processes at each HRU. The official theoretical documentation [45] and a review paper [46] gives more details regarding the SWAT model. The ArcSWAT (Version 2012.10_4.21) is used for generating SWAT inputs in this study.

Besides meteorological data, the SWAT model also needs elevation data, land use, and soil maps. Digital elevation models (DEM) with $90 \mathrm{~m}$ resolution were downloaded from the United States Geological Survey (USGS). Land use data were acquired from the Environmental and Ecological Science Data Center for West China, the National Natural Science Foundation of China (http://westdc.westgis.ac.cn). The soil data were obtained from the China Soil Dataset (v1.1), which is based on the World Soil Database (HWSD). The soil water characteristics of each soil type were obtained utilizing the SPAW software [47].

By varying different precipitation and temperature data as inputs, a total of 6 models were set up using a combination of two temperature data (gauge and CFSR) and three precipitation data (GSMaP_Gauge, CHIRPS, and CFSR) to study the effects of different weather products on streamflow simulation.

\subsection{Model calibration and evaluation}

The SUFI-2 algorithm in the SWAT-CUP software package is employed for the SWAT model calibration, uncertainty, and sensitivity analysis. The SUFI2 algorithm covers all uncertainties (parameter, conceptual model and input) of the parameters [48]. It calculates 95\% PPU at the $2.5 \%$ and $97.5 \%$ levels of the cumulative probability distribution of an output variable obtained through Latin hypercube sampling disallowing $5 \%$ of the very bad simulations $[48,49]$. P-factor and R-factor are used to evaluate the strength of model calibration and uncertainty. The P-factor varies from 0 to 1, where 1 indicates 100 bracketings of the measured data within model prediction uncertainty [50]. The R-factor represents the ratio of the average width of the 95\% PPU band and the standard deviation of the observed variable. There are ten objective functions such as $\mathrm{R}^{2}$, Nash-Sutcliff (NS) to evaluate the simulated results. In this paper, we used $\mathrm{R}^{2}$, NS, and (Percent Bias) PBIAS to evaluate the accuracy of the result. The formulas are as follows:

$$
R^{2}=\frac{\left[\sum_{i}\left(Q_{m, i}-\overline{Q_{m}}\right)\left(Q_{s, i}-\overline{Q_{s}}\right)\right]^{2}}{\sum_{i}\left(Q_{m, i}-\overline{Q_{m}}\right)^{2} \sum_{i}\left(Q_{s, i}-\overline{Q_{s}}\right)^{2}}
$$




$$
\begin{array}{r}
N S=1-\frac{\sum_{i=1}\left(Q_{m}-Q_{s}\right)_{i}{ }^{2}}{\sum_{i=1}\left(Q_{m, i}-\overline{Q_{m}}\right)^{2}} \\
\text { PBIAS }=100 \cdot \frac{\sum_{i=1}^{n}\left(Q_{m}-Q_{s}\right)_{i}}{\sum_{i=1}^{n} Q_{m, i}}
\end{array}
$$

where $Q$ is a variable (discharge in here), $m$ and $s$ stand for the measured and simulated variable, $i$ represents the $i$ th measured or simulated data, and the bar stands for average. The optimum values of $\mathrm{R}^{2}$, NS, and PBIAS are 1, 1 and 0 respectively. For an even comparison, models are evaluated after an equal number of iterations.

\subsection{Results}

\subsection{Comparison of precipitation and temperature products}

The comparison of different satellite-based precipitation products can help to identify the consistency and discrepancy that exist between them. Figure 2 shows the spatial patterns of annual precipitation estimates from gauged and 3 satellite products. Generally, these precipitation products have similar patterns, showing a decreasing trend from southwest to northeast. However, the precipitation from the 3 satellite products displayed large differences over the study area. The mean annual precipitation for the GSMaP_Gauge, CHIRPS, and CFSR are 255.2, 238.4 and $351.4 \mathrm{~mm} / \mathrm{yr}$, respectively. The CFSR precipitation generally has the largest value followed by CHIRPS and GSMaP_Gauge, and the maximum difference in annual precipitation between the two products was larger than $100 \mathrm{~mm} / \mathrm{yr}$.

(a) Observed $270.8 \mathrm{~mm} / \mathrm{yr}$

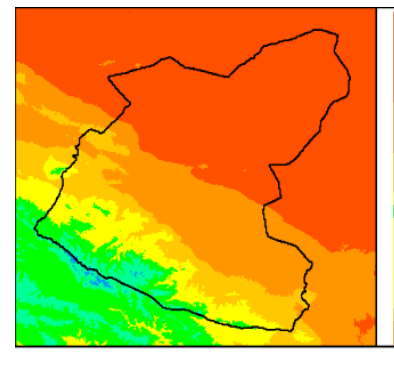

(b) GSMaP $263.4 \mathrm{~mm} / \mathrm{yr}$

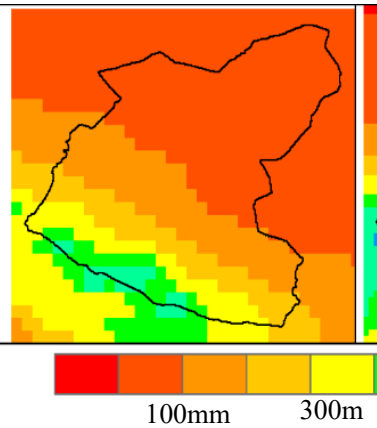

(c) CHIRPS $287.3 \mathrm{~mm} / \mathrm{yr}$

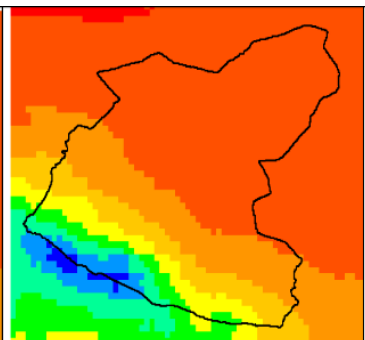

(d) CFSR $351.4 \mathrm{~mm} / \mathrm{yr}$

Fig 2. The spatial pattern of the mean annual precipitation over the study area for GSMap (a), CHIRPS (b) and CFSR (c) datasets during the period of 2000 to 2012.

Fig. 3 shows the cumulative basin averaged daily precipitation for four products from 2000 to 2012. Four daily precipitation products displayed different probability of occurrence for the dry day (rain $=0 \mathrm{~mm} /$ day), which are $49 \%, 52 \%, 68 \%$ and $20 \%$ for gauge, GSMaP_Gauge, CHIRPS, and CFSR, respectively. Overall, GSMaP_Gauge and CHIRPS had similar distribution for all precipitation intensity. CFSR product was significantly different from other products except for high wet days $(>15 \mathrm{~mm})$. CFSR data set had the highest probability (11\%) of precipitation beyond $5 \mathrm{~mm} /$ day, while others had less than $5 \%$. 

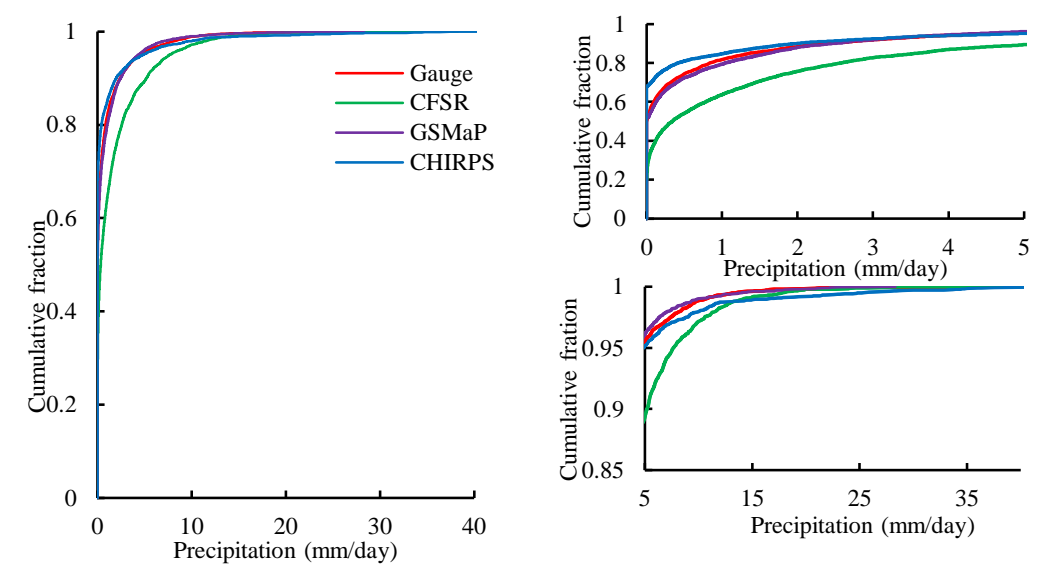

Fig. 3 The cumulative fraction of daily precipitation from four datasets (Gauge, GSMaP, CHIRPS, and CFSR) at the basin scale from 2000-2012.

Fig. 4 displays the comparison of monthly precipitation over the basin from four datasets during the calibration and validation period. These datasets showed the same seasonal pattern with wet months that occurred June-September. However, CFSR generally had more precipitation than the other three datasets for the wet months throughout the entire period. The variation and magnitude of monthly precipitation for GSMaP_Gauge and CHIRPS precipitation data were much similar, which were also similar to gauged precipitation, but their peaks were usually higher than gauged precipitation.

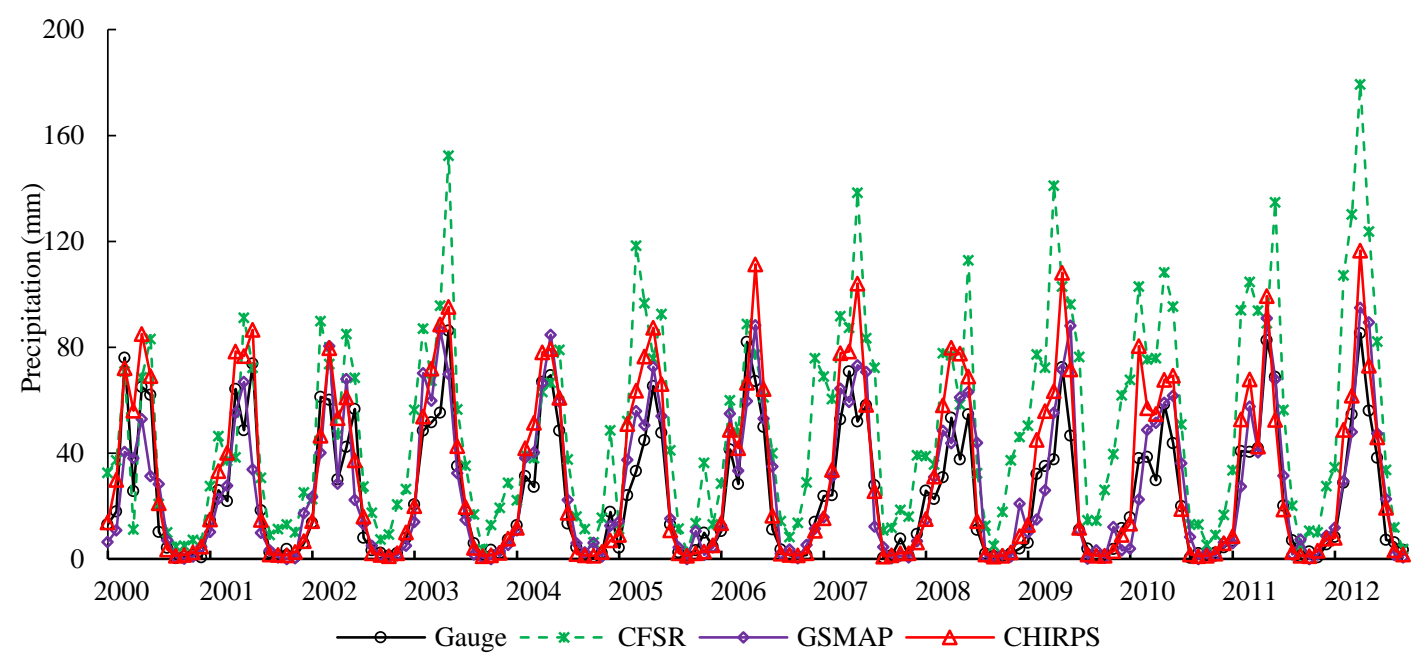

Fig. 4 Comparison of monthly precipitation totals from four datasets (gauge, GSMaP, CHIRPS, and CFSR) at the basin scale from 2000-2012.

Fig. 5 shows the comparison of cumulative fraction for daily maximum and minimum air temperature at the basin scale from the two precipitation products (gauge and CFSR). Overall, the CFSR dataset agreed better with gauge measurements for the daily minimum air temperature than for maximum air temperature. Fig. 6 shows the variations of monthly mean maximum and minimum air temperature from 2000 to 2012. The two datasets showed good similarity in seasonal patterns and 
magnitude during the entire period, with higher temperatures in June-September.
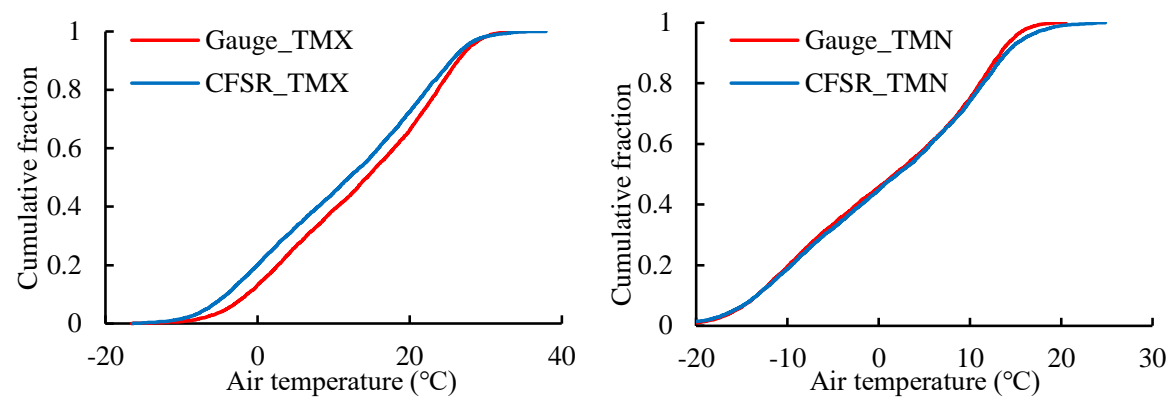

Fig. 5 The cumulative fraction of daily maximum (TMX) and minimum (TMN) air temperature from two data sets (gauge and CFSR) at the basin scale from 2000-2012.

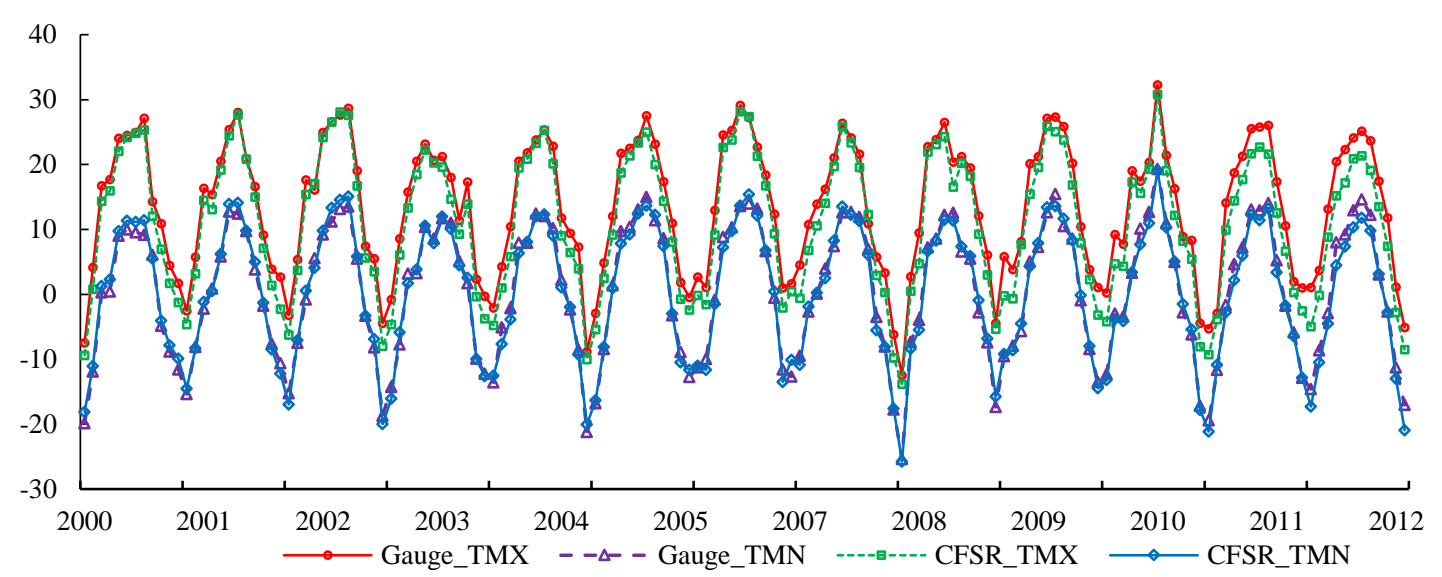

Fig. 6 Comparison of monthly maximum (TMX) and minimum (TMN) air temperature from two data sets (gauge and CFSR) at the basin scale from 2000-2012.

\subsection{Comparison of streamflow simulation with different precipitation and temperature products}

\subsubsection{Streamflow simulation without calibration}

We first evaluated the performance of six model scenarios without calibration in three stations, and for conciseness, the streamflow graphs without calibration are not shown here. Table 1 shows the evaluation statistics for the performance of six models in three stations. Moriasi et al. [51] indicated that model simulation can be judged as satisfactory if NSE $>0.5$ and PBIAS $< \pm 25 \%$ for streamflow. According to these criteria, using CHIRPS as inputs generated the best performance. In Jiutiaoling and Zamu stations, the models with CHIRPS produced satisfactory streamflow simulations for both periods of calibration (2002-2007) and validation (2008-2012). The models with the same precipitation data and different temperature data generated similar performance. The models that employed CFSR precipitation as inputs resulted in the worst performance in all the three stations for the calibration and validation periods, with minus NS values and higher minus PBIAS values. This is due to the high overestimation of CFSR precipitation (Fig. 2, 4), which indicated that CFSR precipitation is unsuitable for this area.

Table 1. Evaluation statistics for the performance of six models in monthly streamflow simulation.

\begin{tabular}{ccccc}
\hline Station Precipitation Temperature & \multicolumn{2}{c}{ without calibration } & \multicolumn{2}{c}{ after calibration } \\
\cline { 2 - 4 } & $2002-2007$ & $2008-2012$ & $2002-2007$ & $2008-2012$ \\
\hline
\end{tabular}




\begin{tabular}{|c|c|c|c|c|c|c|c|c|c|c|c|c|c|c|}
\hline & & & & & & & & & & & & & & \\
\hline & & & NS & $\mathrm{R}^{2}$ & PBIAS & NS & $\mathrm{R}^{2}$ & PBIAS & NS & $\mathrm{R}^{2}$ & PBIAS & NS & $\mathrm{R}^{2}$ & PBIAS \\
\hline \multirow{6}{*}{ Xida } & \multirow[t]{2}{*}{ GSMAP } & gauge & -0.25 & 0.50 & 66.00 & -0.10 & 0.51 & 57.70 & 0.55 & 0.69 & 24.60 & 0.64 & 0.73 & 21.00 \\
\hline & & CFSR & -0.05 & 0.48 & 57.30 & -0.07 & 0.32 & 66.20 & 0.63 & 0.70 & 17.70 & 0.50 & 0.65 & 21.40 \\
\hline & \multirow[t]{2}{*}{ CHIRPS } & gauge & 0.46 & 0.66 & 35.30 & 0.30 & 0.68 & 45.40 & 0.68 & 0.68 & 0.90 & 0.75 & 0.77 & 9.10 \\
\hline & & CFSR & 0.57 & 0.68 & 22.20 & -0.06 & 0.48 & 54.90 & 0.70 & 0.71 & -2.00 & 0.61 & 0.62 & -7.70 \\
\hline & \multirow[t]{2}{*}{ CFSR } & gauge & 0.32 & 0.47 & -11.7 & -1.07 & 0.55 & -71.00 & 0.61 & 0.63 & 8.60 & 0.37 & 0.60 & -30.80 \\
\hline & & CFSR & -0.06 & 0.43 & -27.20 & -3.70 & 0.36 & -102.30 & 0.69 & 0.77 & 20.90 & 0.51 & 0.73 & -24.89 \\
\hline \multirow{6}{*}{ Jiutiaoling } & \multirow[t]{2}{*}{ GSMAP } & gaug & 0.25 & 0.51 & 41.70 & 0.43 & 0.52 & 16.60 & 0.84 & 0.84 & -3.50 & 0.80 & 0.82 & -8.40 \\
\hline & & CFSR & 0.48 & 0.57 & 23.40 & 0.27 & 0.42 & 25.50 & 0.78 & 0.79 & -1.60 & 0.73 & 0.75 & 4.40 \\
\hline & \multirow[t]{2}{*}{ CHIRPS } & gauge & 0.74 & 0.76 & -13.10 & 0.68 & 0.70 & -12.80 & 0.83 & 0.83 & -3.40 & 0.81 & 0.81 & -1.90 \\
\hline & & CFSR & 0.54 & 0.80 & -26.30 & 0.56 & 0.67 & 9.90 & 0.82 & 0.84 & 3.50 & 0.74 & 0.73 & 12.80 \\
\hline & \multirow[t]{2}{*}{ CFSR } & gauge & -3.05 & 0.43 & -121.70 & -7.80 & 0.33 & -191.20 & 0.59 & 0.63 & 17.33 & 0.52 & 0.68 & -18.16 \\
\hline & & CFSR & -5.47 & 0.53 & -146.10 & -13.99 & 0.40 & -127.80 & 0.58 & 0.64 & 21.14 & 0.54 & 0.67 & -13.18 \\
\hline \multirow{6}{*}{ Zamu } & \multirow[t]{2}{*}{ GSMAP } & gauge & 0.04 & 0.40 & 48.60 & 0.33 & 0.42 & 20.60 & 0.76 & 0.76 & -5.70 & 0.84 & 0.84 & -3.20 \\
\hline & & CFSR & 0.31 & 0.45 & 30.10 & 0.08 & 0.27 & 23.10 & 0.79 & 0.79 & 1.80 & 0.70 & 0.68 & 8.50 \\
\hline & \multirow[t]{2}{*}{ CHIRPS } & gauge & 0.70 & 0.77 & 21.80 & 0.71 & 0.76 & 18.70 & 0.80 & 0.81 & 7.20 & 0.80 & 0.80 & 8.20 \\
\hline & & CFSR & 0.74 & 0.79 & -2.20 & 0.46 & 0.57 & 20.90 & 0.77 & 0.78 & -3.40 & 0.73 & 0.73 & 4.60 \\
\hline & \multirow[t]{2}{*}{ CFSR } & gauge & -1.05 & 0.43 & -77.6 & -10.07 & 0.43 & -203.50 & 0.56 & 0.69 & 24.82 & 0.45 & 0.61 & -19.76 \\
\hline & & CFSR & -2.37 & 0.47 & -113.10 & -16.23 & 0.43 & -246.70 & 0.54 & 0.62 & 20.77 & 0.20 & 0.51 & -33.48 \\
\hline
\end{tabular}

4.2.2 Streamflow simulation after calibration

Figs. 7-9 presents a comparison of monthly measured and simulated streamflow from six model scenarios in three stations respectively. For brevity, we did not separate the calibration and validation periods but showed the evaluation statistics for the two periods in Table 1. In Fig. 7-9, the first row showed the comparison of measured and simulated streamflow using gauged temperature as input with different precipitation datasets, and the second row showed the same as the first row except that CFSF air temperature was used as input instead of gauge data.

Generally, most models were able to capture seasonal patterns very well. Hydrograph showed reasonable agreement between the observed and simulated streamflow using CHIRPS and GSMaP_Gauge precipitation as inputs except for overestimation and underestimation in a very few events. CHIRPS precipitation performed best in streamflow simulation with NS $>0.60$ in all the three stations (Table 1). In Jiutiaoling station and Zamu stations, NS $>0.80$ and PBIAS $<5 \%$ using CHIRPS and gauge temperature as inputs (Table 1). In Jiutiaoling station, GSMaP _Gauge precipitation even performed better than CHIRPS with NS $>0.84$ and PBIAS $<5 \%$ at the calibration period. However, CHIRPS had overestimation at peak flow period in some years, for example in the year 2010 and 2011 in Xida station. The cause of this phenomenon is the overestimation of daily rainfall from CHIRPS in these months (Fig. 4). Using CFSR precipitation yielded the worst performance in all the three stations. The overestimation of precipitation by CFSR seems to be more severe during the validation period (2008-2012), and thus the calibrated parameters could not compensate for such overestimation.

In summary, using several precipitation datasets as inputs to SWAT had a larger impact on streamflow simulation than using different air temperature datasets in the study area. Using CFSR temperature as input can deliver equal performance to gauge temperature. This is a good sign for researchers and managers that they have an alternative when gauge temperature products are scarce. Regarding the selection of precipitation dataset, we do recommend CHIRPS as input for streamflow simulation in this area. And the combination of CHIRPS precipitation and CFSR air temperature is 
an alternative data source to drive the hydrological model when there is no access to gauge at all.
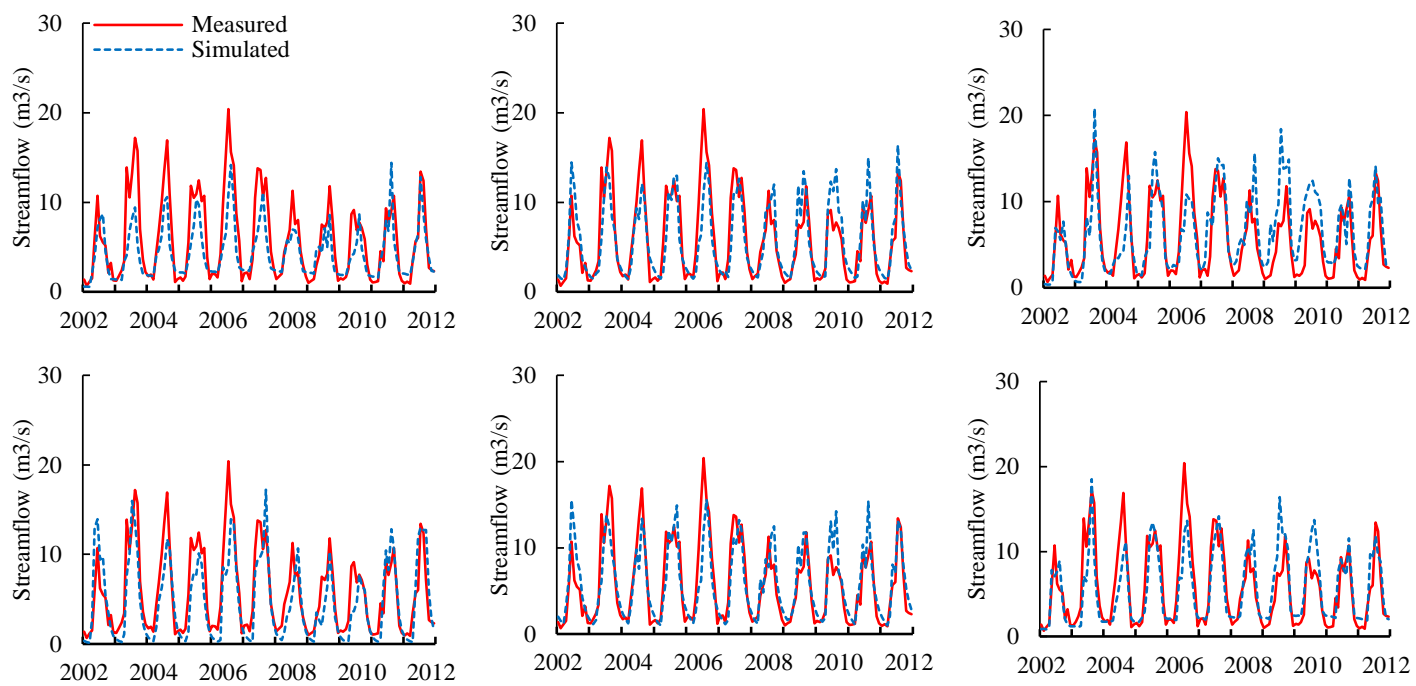

Fig. 7 Comparison of monthly measured and simulated streamflow from models using observed temperature (obs_tmp) and CFSR temperature (CFSR_tmp) with three different precipitation datasets (a: obs_tmp vs. GSMaP, b: CFSR_tmp vs. GSMaP, c: obs_tmp vs. CHIRPS, d: CFSR_tmp vs. CHIRPS, e: obs_tmp vs. CFSR, d: CFSR_tmp vs. CFSR ) for the calibration and validation period at Xida station.
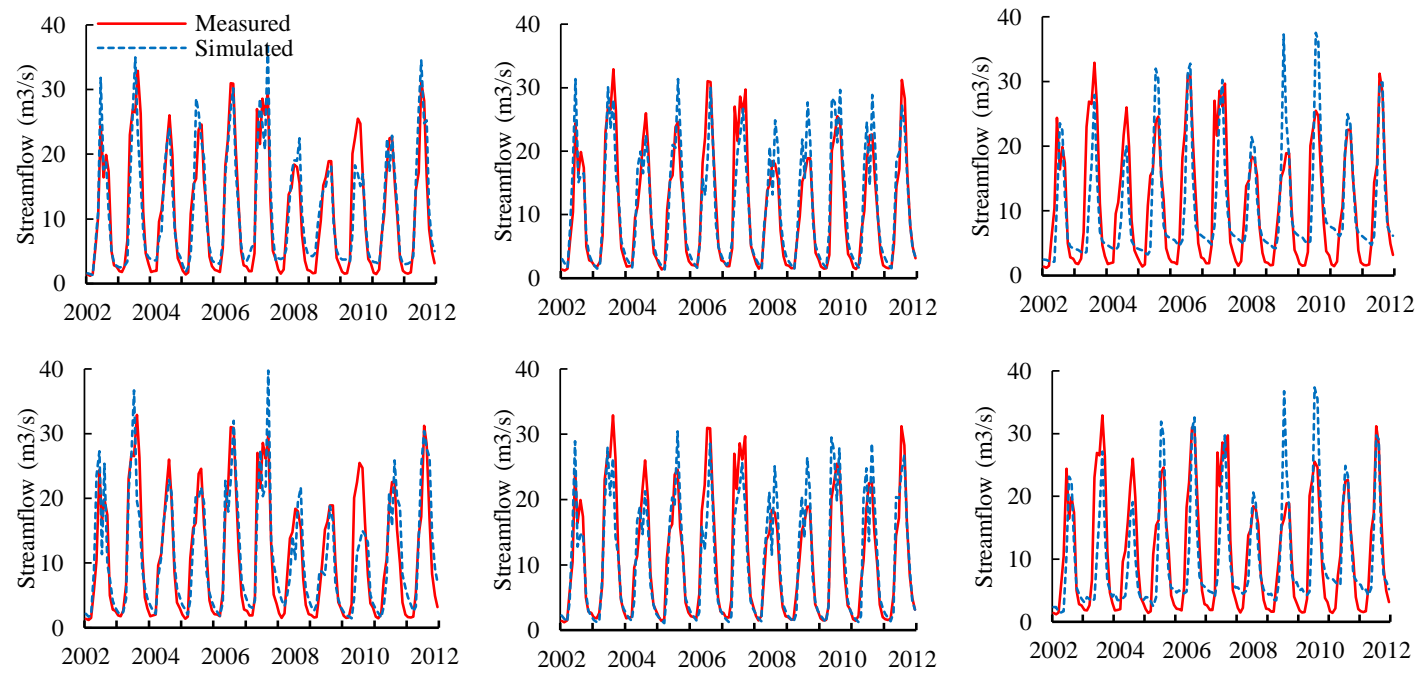

Fig. 8 Comparison of monthly measured and simulated streamflow from models using observed temperature (obs_tmp) and CFSR temperature (CFSR_tmp) with three different precipitation datasets (a: obs_tmp vs. GSMaP, b: CFSR_tmp vs. GSMaP, c: obs_tmp vs. CHIRPS, d: CFSR_tmp vs. CHIRPS, e: obs_tmp vs. CFSR, d: CFSR_tmp vs. CFSR) for the calibration and validation period at Jiutiaoling station.
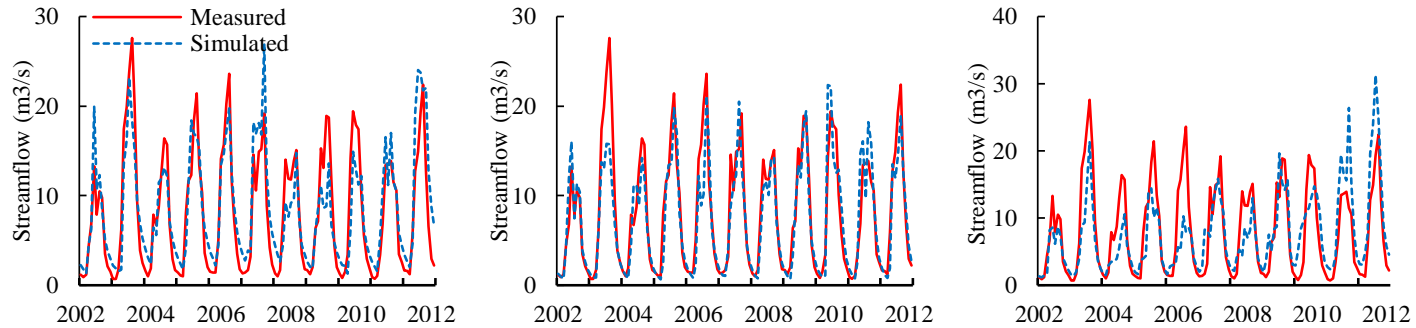

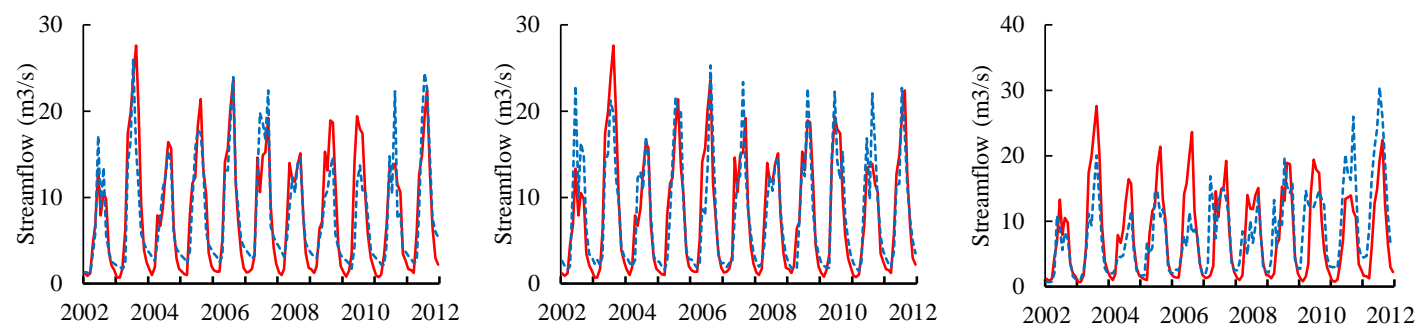

Fig. 9 Comparison of monthly measured and simulated streamflow from models using observed temperature (obs_tmp) and CFSR temperature (CFSR_tmp) with three different precipitation datasets (a: obs_tmp vs. GSMaP, b: CFSR_tmp vs. GSMaP, c: obs_tmp vs. CHIRPS, d: CFSR_tmp vs. CHIRPS, e: obs_tmp vs. CFSR, d: CFSR_tmp vs. CFSR ) for the calibration and validation period at Zamu station.

\subsubsection{Comparison of calibrated parameters}

We compared the differences in parameters from different models taking Jiutiaoling station as a case study. Table 2 shows the optimal parameters after calibration in Jiutiaoling station. Models using gauge temperature and CFSR temperature had similar values when using the same precipitation data to drive the SWAT model. Different models driven by different precipitation products generate diverse optimal parameters, but still yielding similarly good performance, which also reflects the effect of parameters. For example, the optimal parameter CN2 is positive 0.2 with GSMaP_Gauge driving SWAT model and negative with CHIRPS and CFSR. The decrease in CN2 could generally result in less runoff by SWAT. For the parameter SOL_AWC that is responsible for the available water capacity of the soil layer, GSMaP precipitation led to an increase, and CHIRPS and CFSR precipitation datasets resulted in a decrease. The decrease in SOL_AWC could also result in less runoff. For the groundwater delay time (GW_DELAY) parameter, GSMaP precipitation had higher values, which resulted in a slow recharge of the shallow aquifer and discharge to the stream.

During calibration, however, different parameter values compensated the differences in precipitation inputs to increase the performance of streamflow simulation at the basin outlet, which may lead to different hydrological components. This is an intrinsic deficiency using only streamflow to calibrate hydrological models. Unfortunately, this is a common practice in hydrological modelling due to the scarcity of other observed hydrological components (soil moisture, evaporation). Therefore, the multivariable (such as satellite-based evapotranspiration or soil moisture data) or multi-site calibration should be made to overcome the uncertainty of the parameters. Several studies have attempted to examine the feasibility of improving hydrological modelling using satellite soil moisture and evaporation [52-55]. This practice (model calibration with satellite-based evapotranspiration or soil moisture data) is also within our plans for further study in the Shiyang river basin.

Table 2. Optimal parameters calibrated for six models in Jiutiaoling station

\begin{tabular}{ccccccc} 
Parameters & \multicolumn{7}{c}{ Jiutiaoling } \\
\cline { 2 - 7 } PSMAP_GAUGE & \multicolumn{7}{c}{ GSMAP_CFSR CHIRPS_GAUGE CHIRPS_CFSR CFSR_GAUGE CFSR_CFSR } \\
\hline r_CN2 & 0.19 & 0.2 & -0.48 & -0.58 & -0.34 & -0.36 \\
v_SURLAG & 13.58 & 14.33 & 13.83 & 13.51 & 16.2 & 15.42 \\
v_ALPH_BF & 0.64 & 0.7 & 1.57 & 3.08 & 0.59 & 0.64 \\
v_GW_DELAY & 491.25 & 451.88 & 332.03 & 333.8 & 345.47 & 344.79 \\
a_GWQMN & 674 & 681 & 1386.96 & 848.1 & 1661.86 & 1584.29 \\
\hline
\end{tabular}




\begin{tabular}{ccccccc}
\hline v_GW_REVAP & 0.11 & 0.15 & 0.14 & 0.22 & 0.16 & -0.08 \\
v_ESCO & 0.62 & 0.57 & 0.1 & 0.87 & 0.66 & 0.68 \\
r_SOL_AWC & 0.28 & 0.18 & -0.24 & -0.31 & -0.13 & -0.16 \\
v_CH_K2 & 19.88 & 23.25 & 13.62 & 15.14 & 11.22 & 10.61 \\
\hline
\end{tabular}

\section{Discussion}

Precipitation and temperature are the two most significant inputs for streamflow simulation, and inaccuracy from their measurements could lead to large uncertainties in streamflow simulations and predictions $[8,56,57]$. Therefore, the hydrological evaluations of the climatic inputs are based on the hypothesis that errors in the climatic inputs can propagate into the hydrographic outputs [58]. Evaluating climatic inputs through their predictability on streamflow is usually carried out at the watershed scale, which avoids the scale discrepancy compared to using gauge observations for validation [2]. This study compared the model performances for streamflow simulations driven by different precipitation and temperature products derived from satellite data in the Shiyang river basin. Several studies have evaluated the performance of different precipitation datasets in driving hydrological SWAT model in streamflow simulation in the same basin. Guo and Su [34] evaluated the performances of five different satellite and reanalysis precipitation datasets in streamflow simulation of Jiutiaoling station and indicated that CHIRPS and CMDF performed better than other datasets (i.e., TRMM, CFSR, and PGF). They found that CFSR overestimated precipitation and produced unsatisfactory streamflow simulation, which was consistent with our study. Similar overestimation in CFSR precipitation datasets has also been reported in many other regions like Ethiopia [6,59], Singapore [60], Xiang river basin and Qu river basin in China [61] and Mekong river basin [62], with limited research reporting much better performances of CFSR precipitation datasets in streamflow simulations [63]. In contrast, Musie found that the CFSR product underestimated precipitation amounts in the Meki watershed of Ethiopia [59]. That results indicated that CFSR precipitation data have large uncertainty and should be used with caution despite its global availability and free access.

The CHIRPS precipitation product, the replacement of TRMM, is a relatively long dataset spanning from 1978 to date. Some studies have assessed the CHIRPS products and their comparison with other widely used products such as TRMM and CFSR. Results showed that CHIRPS performed better than other products in diverse regions of the world. Beck et al. [64] comprehensively appraised 22 precipitation products using the HBV model and indicated that CHIRPS yielded the most accurate long-term precipitation means due to the use of high resolution gauge-based climatic datasets. Other studies in the Adige basin in Italy [27], Upper Blue Nile basin, Ethiopia [65], East Africa [66] and Haihe River Basin, China [67] were also in line with this result. In the same vein, these studies also agree with our study that the CHIRPS product had a good performance. GSMaP _Gauge and CHIRPS precipitation datasets had similar performance despite their differences in space and time. A viable explanation is that the differences in the precipitation inputs were buffered inside the hydrological model via parameter calibration.

It should be noted that the CHIRPS product only gives daily precipitation despite their finer resolution $\left(0.05^{\circ}\right)$, which hinders its application on streamflow simulation at sub-daily scales. In contrast, CFSR and GSMaP provided hourly rainfall products that are assumed to have beneficial potentials for applications on streamflow simulation at an hourly scale. Compared to CFSR, GSMaP is an assuring product to simulate sub-daily streamflow due to its finer resolution and higher precision. Further research is, therefore, necessary to evaluate the performances of gridded precipitation products at sub-daily scales in future studies. 


\section{Conclusions}

Due to the inadequacy of measured weather datasets in mountainous regions, this research compared the performances of three remote sensing precipitation products (GSMaP_Gauge, CHIRPS, CFSR) and one temperature product (CFSR) in driving SWAT model for simulating streamflow in Shiyang river basin. After a thorough comparison in three hydrologic stations located in upstream, the following conclusions were drawn:

1. The annual precipitation from the three satellite products displays a large disparity over the study area. The CFSR precipitation generally has the largest values, followed by gauged precipitation, CHIRPS and GSMaP_Gauge products. CFSR data set agreed better with gauge measurements for the daily minimum air temperature than for maximum air temperature.

2. The CFSR temperature produced almost the same simulated results with the observed temperature in streamflow simulation for the three stations. This proved the accuracy of using CFSR air temperature for hydrological modelling in this region. This is useful for researchers and the local community as the availability and quality of observed temperatures are often worse than that of precipitation, especially on a daily scale.

3. Among the three precipitation products, CHIRPS yielded the best performance and it was the only one that can achieve satisfactory simulation without calibration. The CFSR overestimated precipitation values and resulted in inconsistent and unsatisfactory performance for monthly streamflow simulation.

4. The CHIRPS precipitation product with a high spatial resolution $\left(0.05^{\circ}\right)$ with the CFSR air temperature can be a promising alternative open-access data source for streamflow simulation with SWAT in data-scarce areas.

This study did not analyze the performance of using complete CFSR weather data (wind speed, solar radiation, and relative humidity) for driving the SWAT on account of non-availability of measured datasets. This is an interesting topic for future studies. Besides, studies could also include further testing of CHIRPS or other open-access data in more different regions, and the added values of currently available satellite products in constraining calibration and spatially evaluation of hydrological models particularly in poor and even ungauged basins.

Author Contributions: Gengxi Zhang analyzed the data, and wrote this paper. Xiaoling Su provided technical guidance and revised this manuscript. Olusola O. Ayantobo revised the manuscript and improved the language. Kai Feng and Jing Guo revised the manuscript.

Funding: This work is financially supported by the National Natural Science Foundation of China (grant numbers 51879222 and 91425302) and the China Scholarship Council (201906300059).

Acknowledgements: We thank all providers as specified in Section 3 of this paper for providing datasets for this study.We thank the anonymous reviewers for their critical and insightful comments and suggestions that improved this paper. Our gratitude also goes to the editorial team of Remote Sensing.

Conflicts of Interest: The authors declare no conflict of interest.

\section{References}

1. Tuo, Y.; Duan, Z.; Disse, M.; Chiogna, G. Evaluation of precipitation input for SWAT modeling in Alpine catchment: A case study in the Adige river basin (Italy). Science of the Total Environment 2016, 573, 66-82, doi:10.1016/j.scitotenv.2016.08.034. 
2. Bai, P.; Liu, X. Evaluation of Five Satellite-Based Precipitation Products in Two Gauge-Scarce Basins on the Tibetan Plateau. Remote Sensing 2018, 10, doi:10.3390/rs10081316.

3. Vergara, H.; Hong, Y.; Gourley, J.J.; Anagnostou, E.N.; Maggioni, V.; Stampoulis, D.; Kirstetter, P.-E. Effects of Resolution of Satellite-Based Rainfall Estimates on Hydrologic Modeling Skill at Different Scales. Journal of Hydrometeorology 2014, 15, 593-613, doi:10.1175/jhm-d-12-0113.1.

4. Ward, E.; Buytaert, W.; Peaver, L.; Wheater, H. Evaluation of precipitation products over complex mountainous terrain: A water resources perspective. Advances in Water Resources 2011, 34, 1222-1231, doi:https://doi.org/10.1016/j.advwatres.2011.05.007.

5. Tan, X.; Yong, B.; Ren, L. Error features of the hourly GSMaP multi-satellite precipitation estimates over nine major basins of China. Hydrology Research 2018, 49, 761-779, doi:10.2166/nh.2017.263.

6. Deng, P.; Zhang, M.; Bing, J.; Jia, J.; Zhang, D. Evaluation of the GSMaP_Gauge products using rain gauge observations and SWAT model in the Upper Hanjiang River Basin. Atmospheric Research 2019, 219, 153-165, doi:10.1016/j.atmosres.2018.12.032.

7. Liu, X.; Yang, T.; Hsu, K.; Liu, C.; Sorooshian, S. Evaluating the streamflow simulation capability of PERSIANN-CDR daily rainfall products in two river basins on the Tibetan Plateau. Hydrology and Earth System Sciences 2017, 21, 169-181, doi:10.5194/hess-21-169-2017.

8. Duan, Z.; Tuo, Y.; Liu, J.; Gao, H.; Song, X.; Zhang, Z.; Yang, L.; Mekonnen, D.F. Hydrological evaluation of open-access precipitation and air temperature datasets using SWAT in a poorly gauged basin in Ethiopia. Journal of Hydrology 2019, 569, 612-626, doi:10.1016/j.jhydrol.2018.12.026.

9. Thiemig, V.; Rojas, R.; Zambrano-Bigiarini, M.; Levizzani, V.; De Roo, A. Validation of Satellite-Based Precipitation Products over Sparsely Gauged African River Basins. Journal of Hydrometeorology 2012, 13, 1760-1783, doi:10.1175/jhm-d-12-032.1.

10. Li, H.; Hong, Y.; Xie, P.; Gao, J.; Niu, Z.; Kirstetter, P.; Yong, B. Variational merged of hourly gauge-satellite precipitation in China: Preliminary results. Journal of Geophysical Research: Atmospheres 2015, 120, 9897-9915, doi:10.1002/2015jd023710.

11. Vasiloff, S.V.; Seo, D.-J.; Howard, K.W.; Zhang, J.; Kitzmiller, D.H.; Mullusky, M.G.; Krajewski, W.F.; Brandes, E.A.; Rabin, R.M.; Berkowitz, D.S., et al. Improving QPE and Very Short Term QPF: An Initiative for a Community-Wide Integrated Approach. Bulletin of the American Meteorological Society 2007, 88, 1899-1911, doi:10.1175/bams-88-12-1899.

12. Mei, Y.; Nikolopoulos, E.; Anagnostou, E.; Zoccatelli, D.; Borga, M. Error Analysis of Satellite Precipitation-Driven Modeling of Flood Events in Complex Alpine Terrain. Remote Sensing 2016, 8, doi:10.3390/rs8040293.

13. Funk, C.; Peterson, P.; Landsfeld, M.; Pedreros, D.; Verdin, J.; Shukla, S.; Husak, G.; Rowland, J.; Harrison, L.; Hoell, A., et al. The climate hazards infrared precipitation with stations--a new environmental record for monitoring extremes. Sci Data 2015, 2, 150066, doi:10.1038/sdata.2015.66.

14. Marra, F.; Morin, E.; Peleg, N.; Mei, Y.; Anagnostou, E.N. Intensity-duration-frequency curves from remote sensing rainfall estimates: comparing satellite and weather radar over the eastern Mediterranean. Hydrology and Earth System Sciences 2017, 21, 2389-2404, doi:10.5194/hess-21-2389-2017.

15. Gottardi, F.; Obled, C.; Gailhard, J.; Paquet, E. Statistical reanalysis of precipitation fields based on ground network data and weather patterns: Application over French mountains. 
Journal of Hydrology 2012, 432-433, 154-167, doi:10.1016/j.jhydrol.2012.02.014.

16. Ning, S.; Song, F.; Udmale, P.; Jin, J.; Thapa, B.R.; Ishidaira, H. Error Analysis and Evaluation of the Latest GSMap and IMERG Precipitation Products over Eastern China. Advances in Meteorology 2017, 2017, 1-16, doi:10.1155/2017/1803492.

17. Aonashi, K.; Awaka, J.; Hirose, M.; Kozu, T.; Kubota, T.; Liu, G.; Shige, S.; Kida, S.; Seto, S.; Takahashi, N., et al. GSMaP Passive Microwave Precipitation Retrieval Algorithm : Algorithm Description and Validation. Journal of the Meteorological Society of Japan 2009, $87 \mathrm{~A}$, 119-136, doi:10.2151/jmsj.87A.119.

18. Kubota, T.; Ushio, T.; Shige, S.; Kida, S.; Kachi, M.; Okamoto, K.i. Verification of HighResolution Satellite-Based Rainfall Estimates around Japan Using a Gauge-Calibrated Ground-Radar Dataset. Journal of the Meteorological Society of Japan 2009, 87A, 203-222, doi:10.2151/jmsj.87A.203.

19. Dinku, T.; Ruiz, F.; Connor, S.J.; Ceccato, P. Validation and Intercomparison of Satellite Rainfall Estimates over Colombia. Journal of Applied Meteorology and Climatology 2010, 49, 1004-1014, doi:10.1175/2009jamc2260.1.

20. Guo, D.; Wang, H.; Zhang, X.; Liu, G. Evaluation and Analysis of Grid Precipitation Fusion Products in Jinsha River Basin Based on China Meteorological Assimilation Datasets for the SWAT Model. Water 2019, 11, 253, doi:10.3390/w11020253.

21. Lu, D.; Yong, B. Evaluation and Hydrological Utility of the Latest GPM IMERG V5 and GSMaP V7 Precipitation Products over the Tibetan Plateau. Remote Sensing 2018, 10, 2022, doi:10.3390/rs10122022.

22. Li, D.; Christakos, G.; Ding, X.; Wu, J. Adequacy of TRMM satellite rainfall data in driving the SWAT modeling of Tiaoxi catchment (Taihu lake basin, China). Journal of Hydrology 2018, 556, 1139-1152, doi:10.1016/j.jhydrol.2017.01.006.

23. Dile, Y.T.; Srinivasan, R. Evaluation of CFSR climate data for hydrologic prediction in datascarce watersheds: an application in the Blue Nile River Basin. JAWRA Journal of the American Water Resources Association 2014, 50, 1226-1241, doi:10.1111/jawr.12182.

24. Ma, D.; Xu, Y.P.; Gu, H.; Zhu, Q.; Sun, Z.; Xuan, W. Role of satellite and reanalysis precipitation products in streamflow and sediment modeling over a typical alpine and gorge region in Southwest China. Science of the Total Environment 2019, 685, 934-950, doi:10.1016/j.scitotenv.2019.06.183.

25. Yang, Y.; Wang, G.; Wang, L.; Yu, J.; Xu, Z. Evaluation of gridded precipitation data for driving SWAT model in area upstream of Three Gorges Reservoir. PloS One 2014, 9, e112725, doi:10.1371/journal.pone.0112725.

26. Radcliffe, D.E.; Mukundan, R. PRISMvs. CFSR Precipitation Data Effects on Calibration and Validation of SWAT Models. JAWRA Journal of the American Water Resources Association 2017, 53, 89-100, doi:10.1111/1752-1688.12484.

27. Duan, Z.; Liu, J.; Tuo, Y.; Chiogna, G.; Disse, M. Evaluation of eight high spatial resolution gridded precipitation products in Adige Basin (Italy) at multiple temporal and spatial scales. Science of the Total Environment 2016, 573, 1536-1553, doi:10.1016/j.scitotenv.2016.08.213.

28. Wu, Y.; Guo, L.; Zheng, H.; Zhang, B.; Li, M. Hydroclimate assessment of gridded precipitation products for the Tibetan Plateau. Science of the Total Environment 2019, 660, 15551564, doi:10.1016/j.scitotenv.2019.01.119.

29. Bai, L.; Shi, C.; Li, L.; Yang, Y.; Wu, J. Accuracy of CHIRPS Satellite-Rainfall Products over Mainland China. Remote Sensing 2018, 10, doi:10.3390/rs10030362. 
30. Paredes-Trejo, F.J.; Barbosa, H.A.; Lakshmi Kumar, T.V. Validating CHIRPS-based satellite precipitation estimates in Northeast Brazil. Journal of Arid Environments 2017, 139, 26-40, doi:10.1016/j.jaridenv.2016.12.009.

31. Su, X.; Li, J.; Singh, V.P. Optimal Allocation of Agricultural Water Resources Based on Virtual Water Subdivision in Shiyang River Basin. Water Resources Management 2014, 28, 2243-2257, doi:10.1007/s11269-014-0611-5.

32. Guo, J.; Su, X.; Singh, V.; Jin, J. Impacts of Climate and Land Use/Cover Change on Streamflow Using SWAT and a Separation Method for the Xiying River Basin in Northwestern China. Water 2016, 8, doi:10.3390/w8050192.

33. Wang, Z.; Ficklin, D.L.; Zhang, Y.; Zhang, M. Impact of climate change on streamflow in the arid Shiyang River Basin of northwest China. Hydrological Processes 2012, 26, 2733-2744, doi:10.1002/hyp.8378.

34. Guo, J.; Su, X. Parameter sensitivity analysis of SWAT model for streamflow simulation with multisource precipitation datasets. Hydrology Research 2019, 50, 861-877, doi:10.2166/nh.2019.083.

35. Wang, Y.; Zhao, J.; Fu, J.; Wei, W. Effects of the Grain for Green Program on the water ecosystem services in an arid area of China-Using the Shiyang River Basin as an example. Ecological Indicators 2019, 104, 659-668, doi:10.1016/j.ecolind.2019.05.045.

36. Mega, T.; Ushio, T.; Takahiro, M.; Kubota, T.; Kachi, M.; Oki, R. Gauge-Adjusted Global Satellite Mapping of Precipitation. IEEE Transactions on Geoscience and Remote Sensing 2019, 57, 1928-1935, doi:10.1109/tgrs.2018.2870199.

37. Saha, S.; Moorthi, S.; Wu, X.; Wang, J.; Nadiga, S.; Tripp, P.; Behringer, D.; Hou, Y.-T.; Chuang, H.-y.; Iredell, M., et al. The NCEP Climate Forecast System Version 2. Journal of Climate 2014, 27, 2185-2208, doi:10.1175/jcli-d-12-00823.1.

38. Xie, P.; Chen, M.; Yang, S.; Yatagai, A.; Hayasaka, T.; Fukushima, Y.; Liu, C. A gauge-based analysis of daily precipitation over East Asia. Journal of Hydrometeorology 2007, 8, 607-626, doi:10.1175/jhm583.1.

39. Ushio, T.; Sasashige, K.; Kubota, T.; Shige, S.; Okamoto, K.i.; Aonashi, K.; Inoue, T.; Takahashi, N.; Iguchi, T.; Kachi, M., et al. A Kalman Filter Approach to the Global Satellite Mapping of Precipitation (GSMaP) from Combined Passive Microwave and Infrared Radiometric Data. Journal of the Meteorological Society of Japan 2009, 87 A, 137-151, doi:10.2151/jmsj.87A.137.

40. Toté, C.; Patricio, D.; Boogaard, H.; van der Wijngaart, R.; Tarnavsky, E.; Funk, C. Evaluation of Satellite Rainfall Estimates for Drought and Flood Monitoring in Mozambique. Remote Sensing 2015, 7, 1758-1776, doi:10.3390/rs70201758.

41. Funk, C.; Peterson, P.; Landsfeld, M.; Pedreros, D.; Verdin, J.; Rowland, J.; Romero, B.; Husak, G.; Michaelsen, J.; Verdin, A. A quasi-global precipitation time series for drought monitoring U.S. Geological Survey: Reston, VA, USA, 2014.

42. Zhang, Y.; Zhang, S.; Zhai, X.; Xia, J. Runoff variation and its response to climate change in the Three Rivers Source Region. Journal of Geographical Sciences 2012, 22, 781-794, doi:10.1007/s11442-012-0963-9.

43. Wu, L.; Su, X.; Ma, X.; Kang, Y.; Jiang, Y. Integrated modeling framework for evaluating and predicting the water resources carrying capacity in a continental river basin of Northwest China. Journal of Cleaner Production 2018, 204, 366-379, doi:10.1016/j.jclepro.2018.08.319.

44. Malago, A.; Bouraoui, F.; Vigiak, O.; Grizzetti, B.; Pastori, M. Modelling water and nutrient fluxes in the Danube River Basin with SWAT. Science of the Total Environment 2017, 603-604, 
196-218.

45. Neitsch, S.L.; Arnold, J.G.; Kiniry, J.R.; R, W.J. Soil and water assessment tool theoretical documentation version 2009; Texas Water Resources Institute, 2011.

46. Gassman, P.W.; Reves, M.R.; Green, C.H.; Arnold , J.G. The soil and water assessment tool: historical development, applications, and future research directions. American Society of Agricultural and Biological Engineers 2007, 50, 1211-1250.

47. Saxton, K.E.; Rawls, W.J. Soil Water Characteristic Estimates by Texture and Organic Matter for Hydrologic Solutions. Soil Science Society of America Journal 2006, 70, doi:10.2136/sssaj2005.0117.

48. Abbaspour, K.C.; Yang, J.; Maximov, I.; Siber, R.; Bogner, K.; Mieleitner, J.; Zobrist, J.; Srinivasan, R. Modelling hydrology and water quality in the pre-alpine/alpine Thur watershed using SWAT. Journal of Hydrology 2007, 333, 413-430, doi:10.1016/j.jhydrol.2006.09.014.

49. Kumar, N.; Singh, S.K.; Srivastava, P.K.; Narsimlu, B. SWAT Model calibration and uncertainty analysis for streamflow prediction of the Tons River Basin, India, using Sequential Uncertainty Fitting (SUFI-2) algorithm. Modeling Earth Systems and Environment 2017, 3, doi:10.1007/s40808-017-0306-z.

50. Abbaspour, K.C.; Rouholahnejad, E.; Vaghefi, S.; Srinivasan, R.; Yang, H.; Kløve, B. A continental-scale hydrology and water quality model for Europe: Calibration and uncertainty of a high-resolution large-scale SWAT model. Journal of Hydrology 2015, 524, 733-752, doi:10.1016/j.jhydrol.2015.03.027.

51. Moriasi, D.N.; Arnold , J.G.; Van Liew, M.W.; Bingner, R.L.; Harmel, R.D.; Veith, T.L. Model evaluation guidlines for systemmatic quantification of accuracy in watershed simulations. Transactions of the ASABE 2007, 50, 885-900.

52. Becker, R.; Koppa, A.; Schulz, S.; Usman, M.; aus der Beek, T.; Schüth, C. Spatially distributed model calibration of a highly managed hydrological system using remote sensing-derived ET data. Journal of Hydrology 2019, 577, doi:10.1016/j.jhydrol.2019.123944.

53. Kundu, D.; Vervoort, R.W.; van Ogtrop, F.F. The value of remotely sensed surface soil moisture for model calibration using SWAT. Hydrological Processes 2017, 31, 2764-2780, doi:10.1002/hyp.11219.

54. Rajib, A.; Merwade, V.; Yu, Z. Rationale and Efficacy of Assimilating Remotely Sensed Potential Evapotranspiration for Reduced Uncertainty of Hydrologic Models. Water Resources Research 2018, 54, 4615-4637, doi:10.1029/2017wr021147.

55. Rajib, M.A.; Merwade, V.; Yu, Z. Multi-objective calibration of a hydrologic model using spatially distributed remotely sensed/in-situ soil moisture. Journal of Hydrology 2016, 536, $192-$ 207, doi:10.1016/j.jhydrol.2016.02.037.

56. Hong, Y.; Hsu, K.-1.; Moradkhani, H.; Sorooshian, S. Uncertainty quantification of satellite precipitation estimation and Monte Carlo assessment of the error propagation into hydrologic response. Water Resources Research 2006, 42, doi:10.1029/2005wr004398.

57. Nijssen, B. Effect of precipitation sampling error on simulated hydrological fluxes and states: Anticipating the Global Precipitation Measurement satellites. Journal of Geophysical Research 2004, 109, doi:10.1029/2003jd003497.

58. Knoche, M.; Fischer, C.; Pohl, E.; Krause, P.; Merz, R. Combined uncertainty of hydrological model complexity and satellite-based forcing data evaluated in two data-scarce semi-arid catchments in Ethiopia. Journal of Hydrology 2014, 519, 2049-2066, 
doi:10.1016/j.jhydrol.2014.10.003.

59. Musie, M.; Sen, S.; Srivastava, P. Comparison and evaluation of gridded precipitation datasets for streamflow simulation in data scarce watersheds of Ethiopia. Journal of Hydrology 2019, 579, doi:10.1016/j.jhydrol.2019.124168.

60. Tan, M.L.; Chua, V.P.; Tan, K.C.; Brindha, K. Evaluation of TMPA 3B43 and NCEP-CFSR precipitation products in drought monitoring over Singapore. International Journal of Remote Sensing 2018, 39, 2089-2104, doi:10.1080/01431161.2018.1425566.

61. Zhu, Q.; Xuan, W.; Liu, L.; Xu, Y.-P. Evaluation and hydrological application of precipitation estimates derived from PERSIANN-CDR, TRMM 3B42V7, and NCEP-CFSR over humid regions in China. Hydrological Processes 2016, 30, 3061-3083, doi:10.1002/hyp.10846.

62. Tang, X.; Zhang, J.; Gao, C.; Ruben, G.; Wang, G. Assessing the Uncertainties of Four Precipitation Products for Swat Modeling in Mekong River Basin. Remote Sensing 2019, 11, 304, doi:10.3390/rs11030304.

63. Fuka, D.R.; Walter, M.T.; MacAlister, C.; Degaetano, A.T.; Steenhuis, T.S.; Easton, Z.M. Using the Climate Forecast System Reanalysis as weather input data for watershed models. Hydrological Processes 2014, 28, 5613-5623, doi:10.1002/hyp.10073.

64. Beck, H.E.; Vergopolan, N.; Pan, M.; Levizzani, V.; van Dijk, A.I.J.M.; Weedon, G.P.; Brocca, L.; Pappenberger, F.; Huffman, G.J.; Wood, E.F. Global-scale evaluation of 22 precipitation datasets using gauge observations and hydrological modeling. Hydrology and Earth System Sciences 2017, 21, 6201-6217, doi:10.5194/hess-21-6201-2017.

65. Bayissa, Y.; Tadesse, T.; Demisse, G.; Shiferaw, A. Evaluation of Satellite-Based Rainfall Estimates and Application to Monitor Meteorological Drought for the Upper Blue Nile Basin, Ethiopia. Remote Sensing 2017, 9, doi:10.3390/rs9070669.

66. Gebrechorkos, S.H.; Hülsmann, S.; Bernhofer, C. Evaluation of multiple climate data sources for managing environmental resources in East Africa. Hydrology and Earth System Sciences 2018, 22, 4547-4564, doi:10.5194/hess-22-4547-2018.

67. Gao, F.; Zhang, Y.; Ren, X.; Yao, Y.; Hao, Z.; Cai, W. Evaluation of CHIRPS and its application for drought monitoring over the Haihe River Basin, China. Natural Hazards 2018, 92, 155-172, doi:10.1007/s11069-018-3196-0. 